\title{
Spinal Leptomeningeal Metastasis from Gastric Cancer: Case Report
}

\section{Mide Kanserine Bağlı Spinal Leptomeningeal Metastaz: Olgu Sunumu}

\author{
Suna Çokmert ${ }^{1}$, Latife Doğanay ${ }^{2}$, Burak Paköz ${ }^{3}$, Alper Yüksel ${ }^{4}$, Emrah Gezer $^{1}$, Mehmet Niyazi \\ Alakavuklar ${ }^{1}$ \\ ${ }^{1}$ Kent Hastanesi, Tıbbi Onkoloji Bölümü, İzmir \\ ${ }^{2}$ Kent Hastanesi, Patoloji Bölümü, İzmir \\ ${ }^{3}$ Kent Hastanesi, Nöroloji Bölümü, İzmir \\ ${ }^{4}$ Kent Hastanesi, Radyoloji Bölümü, İzmir
}

Dergiye Ulaşma Tarihi: 20/01/2015 Dergiye Kabul Tarihi: 22/02/2015 Doi: 10.5505/aot.2015.02419

\section{ÖZET}

Leptomeninksler, solid tümörlerde nadir rastlanılan bir metastaz bölgesidir. Leptomeningeal metastaz'a en sık neden olan tümörler; meme kanseri, akciğer kanseri, melanom ve lösemi-lenfomalardır. Mide kanserine bağl1 leptomeningeal metastaz, oldukça nadir görülen ancak hızlı seyirli ve kötü prognozlu bir tablodur. Tanı beyin omurilik sıvısının biokimyasal ve sitolojik incelenmesi ve görüntüleme yöntemleri ile konulmaktadır. Leptomeningeal metastaz tedavisinde intratekal kemoterapi ve/veya radyoterapiyi içeren çeşitli seçenekler vardır. Bu yazıda spinal leptomeningeal metastaza yol açan metastatik mide kanserli bir kadın hastayı sunduk. Godalinyumlu kranial manyetik rezonans görüntülemede patoloji saptanmazken, torakal spinal vertebra manyetik rezonans görüntülemede Th1-6 düzeyinde leptomeningeal tutulum izlendi. Beyin-omurilik sıvısının sitolojik incelemesi taşlı yüzük hücresine benzeyen tümör hücrelerini saptadı. Bulgular leptomeningeal metastaz ile uyumluydu.

Anahtar Kelimeler: Menengial karsinomatozis, Mide; Kanser

\begin{abstract}
Leptomeninges are a rare region for metastasis in solid tumors. The most common causes of leptomeningeal metastasis are breast cancer, lung cancer, melanoma and leukemia-lymphomas. Leptomeningeal metastasis associated with gastric cancer is an exceedingly rare condition but it is rapidly progressive and poor prognosis. It is diagnosed with biochemical and cytological examination of the cerebrospinal fluid and imaging. There are several treatment options for patients with LMC, including intrathecal chemotherapy with or without radiotherapy. In this report, we present a women with metastatic gastric cancer leading to spinal leptomeningeal metastasis. While magnetic resonance imaging of the brain showed no pathology, magnetic resonance imaging of the thoracal spinal vertebrae showed leptomeningeal enhancement of Th1-6 level. Cytological examination of the cerebrospinal fluid revealed the tumor cells like signet ring cell. These findings were consistent with leptomeningeal metastasis.
\end{abstract}

Key words: Meningeal Carcinomatosis, Gastric; Cancer

\section{Giriş}

Leptomeningeal karsinomatosis (LMK), tümör hücrelerinin leptomeningeal mesafeye yayılımı ve çoğalmasıdır. Leptomeningeal metastaz (LMM), solid kanserlerin \% 3 ila \% 8'inde ortaya çıktığ 1 tahmin edilen nadir bir durumdur (1). Leptomeninkslere en sik metastaz yapan kanserler; meme, akciğer, melanoma, lenfoma ve lösemilerdir $(1,2)$. Mide kanserine bağl1 leptomeninks metastazı ise, insidensi \% 0.140.24 olarak bildirilen oldukça nadir bir durumdur (1,3). Prognoz oldukça kötü olup, tanıdan genellikle 4-7 hafta içinde ölümle sonuçlanmaktadır. Tanı beyin omurilik sivisının (BOS) biokimyasal ve sitolojik incelemesi ve görüntüleme yöntemleri ile konulmaktadır. Tedavide intratekal kemoterapi ve radyoterapi önerilmektedir $(1,2,3)$. Bu yazıda mide adenokarsinomuna bağlı spinal leptomeningeal metastazı olan olguyu sunuyoruz.

\section{Olgu Sunumu:}

48 yaşında bayan hastanın, 2 aydır var olan bulantı ve kilo kaybı yakınmaları ile yapılan üst gastrointestinal sistem endoskopik incelemesinde, mide korpus kısmında kitle izlenmiş ve kitleden alınan biyopsi ile adeno kanser tanısı konulmuş. Bu tanı ile 2013 yılı 
haziran ayında onkoloji bölümüne başvuran hastanın bulantı ve kilo kaybı yakınmalarına ek olarak, yaklaşık 6 aydır var olan sırt, bel bölgesi ve karın sağ tarafında ağrı yakınmaları mevcuttu.

Özgeçmiş ve soygeçmiş bilgilerinde özellik saptanmayan hastanın fizik muayenesinde, epigastriumda palpasyonla ağrı, vertebra boyunca bas1 yapılan kemik bölgelerinde ağrı tespit edildi, karaciğer total vertikal uzunluğu $\mathrm{cm}$ ve palpasyon ağrılı idi. Laboratuar tetkiklerinde anormallik saptanmadı. Hastada metastatik hastalık varlığ düşünülerek ve evreleme amacıyla yapılan positron emisyon tomografi (PET CT) görüntülemede; mide korpus kısmında suvmax değeri 16 olan $5,6 \mathrm{~cm}$ büyüklüğünde kitle, karaciğerde ve vertebralarda çok sayıda metastaz saptandi. Metastatik mide kanseri tanısiyla dosetaksel, sisplatin, 5-fluorurasil (DCF) kemoterapisi başlanan hastada, 2 kür tedavi sonrası semptomlarda özellikle de karın sağ tarafta ağr1 yakınmasında artma nedeniyle batın ultrasonografi (USG) tetkiki yapıldi; karaciğerdeki lezyonlarda sayı ve boyut olarak artış tespit edildi.

Üst batın bilgisayarlı tomografi tetkiki yapılarak, tomografi görüntülerinin tedavi öncesi yapılan PET CT görüntüleri ile karşılaştırmalı değerlendirilmesi ile karaciğerdeki metastazda progresyonun teyid edilmesi neticesinde tedavi FOLFOX protokolü (5-fluorourasil, folinik asit, oksaliplatin) ile değiştirildi. Bu tedavinin ilk kür uygulaması sonrası baş ağrısı, tüm vücutta ağrı, bulantı ve kusma yakınmalarında şiddetlenme görülen hastaya beyin metastazı şüphesi ile kontraslı kranial manyetik rezonans görüntüleme (MRG) tetkiki yapıld1; kranial parankim veya beyin zarlarında metastaz bulgusu izlenmedi. Yakınmaları artarak devam eden ve ağn kesici tedavilere yanıt alınamayan hastada, baş ağrısı ve bulant1-kusma yakınmalarının şiddetlenmesinden 5 gün sonra ense sertliği tespit edilmesi üzerine lomber ponksiyon yapılarak beyin omurilik sivis1 (BOS) incelemesi yapıldı. Ponksiyon sirasinda BOS basıncı yüksek olarak değerlendirildi, BOS incelemesinde protein $492 \mathrm{mg} / \mathrm{dl}$ (normal değerleri $15-45 \mathrm{mg} / \mathrm{dl}$ ), sodyum $138 \mathrm{mmol} / \mathrm{L}$ (normal değerleri 142-150 mmol/L) ve glukoz $3 \mathrm{mg} / \mathrm{dl}$ (normal değerleri 50-80 mg/dl) olarak bulundu. BOS'un sitolojik incelemesinde taşlı yüzük görünümünde adeno kanser hücresi izlendi ve mide kanserinin metastazı olarak değerlendirildi (Resim 1). Steroid tedavisi başlanan hastada, nörolojik tabloda hızlı bir ilerleme ile idrar ve gaita inkontinansı ve sol hemiparezi tablosu gelişmesi üzerine spinal dorsal MRG tetkiki yapıldı; T1-T6 düzeyleri arasinda spinal kord posteriorunda leptomenenjit ile uyumlu ince leptomeningeal tutulumlar saptand1 (Resim 2). Radyoterapi için hazırlık yapılırken hasta ani gelişen solunum ve dolaşım durması nedeniyle kaybedildi.

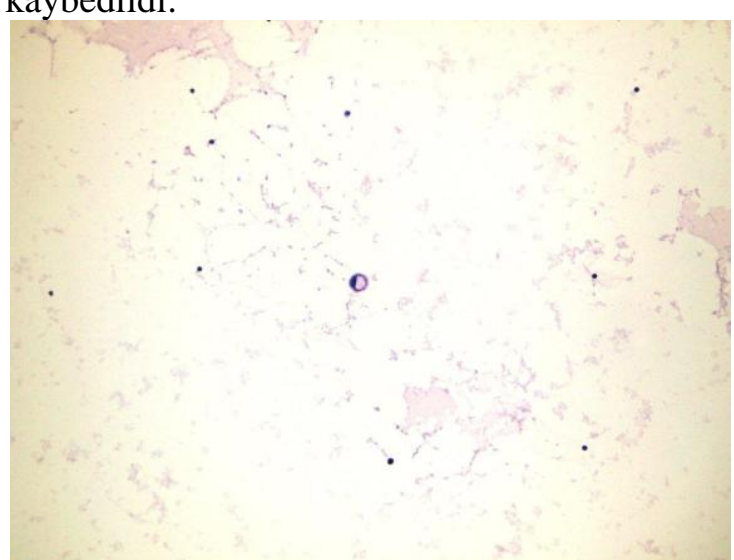

Resim 1: Beyin omurilik sıvısının sitolojik incelemesinde taşlı yüzük görünümünde hücre (okla işaretli hücre)

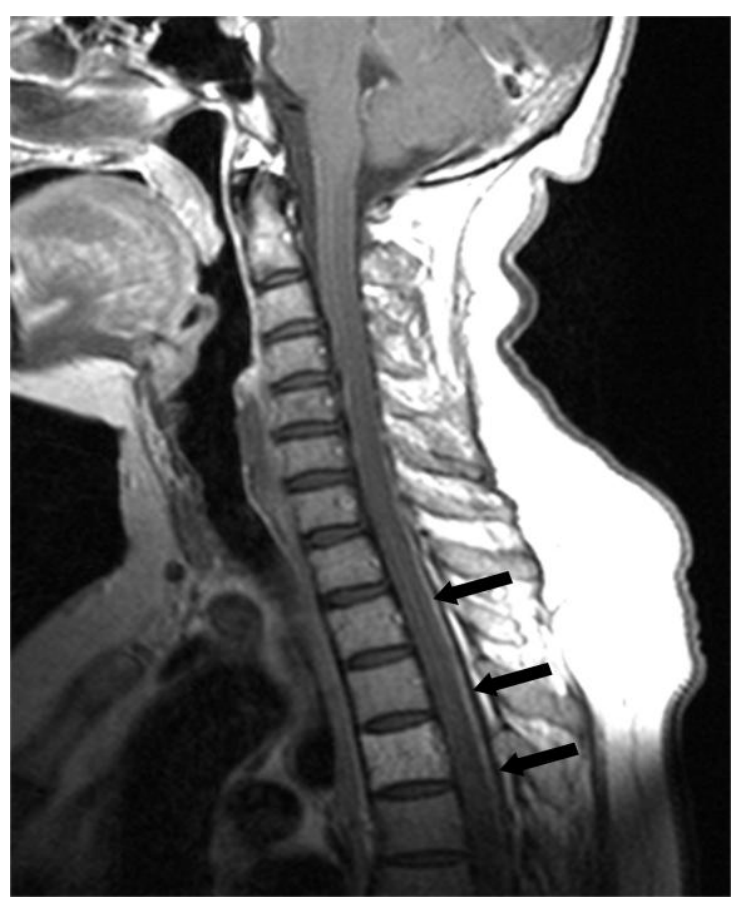

Resim 2: Servikal spinal manyetik rezonans görüntüleme'de,

T1-T6 düzeyleri arasında spinal kord posteriorunda leptomenenjit ile uyumlu ince 
leptomeningeal tutulumlar (okla işaretli bölgeler)

\section{Tartışma:}

Leptomeningeal karsinomatosis, agresif seyirli ve kısa sürede gürültülü nörolojik tablo ile hastayı ölüme götürebilen bir tablodur. Tüm solid kanserlerde görülme sıklığ $1 \%$ 3-8 olarak bildirilse de (1), otopsi serilerinde bu oran \% 20'lere ulaşmaktadır $(2,3)$. Mide kanserine bağlı LMM oldukça nadir bir durumdur; Kim ve arkadaşlarının yaptığı bir çalışmada mide kanserine bağlı LMM insidensi \% 0.06 olarak bildirilirken (4), Lee ve arkadaşları, 11.335 mide kanseri hastası içinde LMM insidensini $\% 0.17$ olarak tespit etmişlerdir (1).

Mide kanserine bağlı LMM, genellikle karaciğer, akciğer, kemik gibi uzak organ metastazlarına eşlik etse de $(2,3,4)$, erken evre mide kanserli bir olguda da LMM bildirilmiştir (5). Mide kanseri tanısından LMM tanısina kadar geçen süre, değişken olmakla beraber 12 ay olarak bildirilmektedir (6). Hastamızda da tanı anında yaygın karaciğer ve vertebral kemiklerde sklerotik metastazlar izlenmekteydi ve mide kanseri tanısı ile LMM teşhisi arasındaki süre 11 aydi.

Leptomeningeal metastaz gelişimine bağlı semptomlar, genellikle hastalığın kendisine bağlı veya tedavisi sirasinda görülebilen yan etkilere benzer olması nedeniyle dikkati çekmeyebilmektedir. En s1k görülen semptomlar, baş ağrısı, bulantı, kusma, ilerleyici güçsüzlük ve işitme kaybıdır (5-8). Hastamızda da benzer şekilde, şiddetli başağrısı, tüm vücutta ağrı ve şiddetli bulantı ve kusma şeklinde başlayan semptomlar, klinikte ense sertliğinin gelişimi, ilerleyici güçsüzlük ve sol hemiparezi, idrar-gaita inkontinansı şeklinde hizlı bir ilerleme göstermiştir.

LMM tanis1 BOS'un sitolojik incelemesi ve görüntüleme tetkikleri ile konulmaktadir $(7,8)$. Lomber ponksiyon sırasında BOS basıncı artmış olarak izlenir ve biokimyasal olarak protein miktarı artarken gukoz düzeyi düşük olarak tespit edilmektedir, yanı sıra hücresel pleositoz ve tümör hücrelerinin varlığ1 izlenmektedir $(1,7)$. Hastaların üçte birinde ilk ponksiyon ve BOS örneğinin diagnostik olmadığı saptanmıştır; Wasserstrom arkadaşları, ilk BOS örneklemesinin diagnostik açıdan duyarlılığını $\% 54$, tekrarlayan örneklemelerde ise \% 91'e ulaştığını bildirmişlerdir (8). Biz hastamızda ilk BOS örneklemesinde gerek biyokimyasal gerekse de sitolojik olarak tanıya ulaşabildik. Literatürde bildirilen vakaların büyük kısmında leptomeningeal metastaza neden olan mide ca histolojik alt tipi, taşlı yüzük hücreli olarak izlenmektedir $(1,9)$. Bizim vakamızda ise histolojik tip adeno kanser olarak tespit edilmekle beraber BOS sitolojisinde tespit edilen hücrede taşlı yüzük görünümü mevcuttu.

Görüntüleme tetkikleri olarak bilgisayarlı tomografi (BT) ve manyetik rezonans görüntüleme (MRG) yapılabilir ancak MRG, BT'ye göre daha üstündür. LMM tanısinda MRG sensivitesinin \% $\quad 65-75$ arasında olduğu bildirilmektedir $(6,10)$. Hastamızda nörolojik bulguların başlaması sirasinda yapılan godalinyumlu kranial MRG'de, LMM saptanmamış olup, BOS'un biokimyasal ve sitolojik incelemesi ile tanı konulabilmiştir. Hastamızda nörolojik bulguların hızla ilerlemesini takiben, sol hemiparezi ve idrar-gaita inkontinansı gelişimi nedeniyle servikal spinal MRG tetkiki yapılmış ve LMM bu tetkikde tespit edilebilmiştir.

Mide kanserine bağlı LMM gelişiminde; arteriel dolaşım, Batson'un venöz pleksusunda retrograd akım, perinöral, perivasküler alanlar ya da lenfatikler yoluyla yayılım ve primer tümör ya da kemik metastazlarından direk yayılım gibi çeşitli yollar ileri sürülmektedir $(10,11)$. Hastamızda nörolojik semptomların başladığı anda, radyolojik olarak kranial parankimal ya da meningeal metastazın olmaması ve spinal leptomeninkslerin tutulmuş olması vertebral kemik metastazlarından perivenöz yayılım ya da subaraknoid alana Batson'ın venöz pleksusu yoluyla yayılımı düşündürmektedir.

LMM tedavisinde standart bir yaklaşım yoktur; sistemik kemoterapi, ilaçların kan beyin bariyerini geçememesi nedeniyle etkili değildir. Bu nedenle kemoterapötiklerin direk olarak intratekal (IT) bölgeye uygulanması önerilmektedir. İT kemoterapide uygulanan ilaçlar metotreksat, sitarabin, tiotepa ve steroidler olup en sik tercih edilen ajan metotreksattır (12). Intratekal kemoterapiye kraniospinal radyoterapi (RT) tedavisi eklenebilir. Tek başına İT kemoterapi veya İT kemoterapi ile beraber RT tedavilerine rağmen prognoz kötüdür. 
Sonuç olarak; mide kanserine bağlı LMM nadir görülen, hızlı seyirli ve ölümcül bir durumdur. Kemoterapi uygulanmas1 sırasında tedaviye dirençli bulantı-kusma ve baş ağrısı yakınması olan mide kanserli hastalarda leptomeningeal metastaz olasilı̆ 1 göz önünde bulundurulmalı ve radyolojik olarak kranial yanısıra spinal bölge de araştırılmalıdır. Radyolojik olarak tanı konulamayan durumlarda BOS incelemesinin tanısal açıdan önemi unutulmamalıdır.

\section{Çıkar Çatışması: Yok}

\section{Kaynaklar:}

1-) Lee JL, Kang YK, Kim TW, et al. Leptomeningeal carcinomatosis in gastric cancer. J Neurooncol. 2004;66 (1-2):167-74.

2-) Pavlidis N: The diagnostic and therapeutic management of leptomeningeal carcinomatosis. Ann Oncol. 2004;15(4):285-91.

3-) Oh SY, Lee SJ, Lee J, et al. Gastric leptomeningeal carcinomoatosis: multi-center retrospective analysis of 54 cases. World J Gastroenterol. 2009;15 (40):5086-90

4-) Kim M. Intracranial involvement by metastatic advanced gastric carcinoma. J Neurooncol. 1999;43

(1):59-62.

5-) Park KK, Yang SI, Seo KW, Kim YO, Yoon KY. A case of metastatic leptomeningeal carcinomatosis from early gastric carcinoma. World Journal of Surgical Oncology. 2012;3; 10:74

6-) Lisenko Y, Kumar AJ, Yao J, Ajani J, Ho L. Leptomeningeal carcinomatosis originating from gastric cancer. Am J Clin Oncol. 2003;26 (2):165-70.
7-) Lee HG, Lee B, Kim SM, Suh BJ, Yu HJ. A Case of Gastric Adenocarcinoma Presenting as Meningeal Carcinomatosis. The Korean Journal of Internal Medicine. 2007;22 (4):304-07.

8-) Wasserstrom WR, Glass JP, Posner JB. Diagnosis and treatment of leptomeningeal metastases from solid tumors: experience with 90 patients. Cancer. 1982;49 (4):759-72.

9-) Giglio P, Weinberg JS, Forman AD, Wolff R, Groves MD. Neoplastic meningitis in patients with adenocarcinoma of the gastrointestinal tract. Cancer. 2005;103 (11):2355-62.

10-) Braeuninger S, Mawrin $C$, Malfertheiner $P$ et al. Gastric adenocarcinoma with leptomeningeal carcinomatosis as the presenting manifestation: an autopsy case report. Eur J Gastroenterol Hepatol. 2005; 17(5):577-79

11-) Batson OV: The role of vertebral veins in metastatic processes. Ann Int Med. 1942; 16:38-45.

12-) Gülcan B, Asuman E, Burçak K, Erdem G. Leptomeningeal carcinomatosis of gastric adenocarcinoma. Turk J Gastroenterol. 2011;22 (2):19598 